\title{
Simultaneous Development of Progressive Multifocal Leukoencephalopathy and Cryptococcal Meningitis during Methotrexate and Infliximab Treatment
}

\author{
Yasunobu Nosaki ${ }^{1}$, Ken Ohyama ${ }^{1}$, Maki Watanabe ${ }^{1}$, Takamasa Yokoi ${ }^{1}$, Kazuo Nakamichi ${ }^{2}$, \\ Masayuki Saijo $^{2}$, Yoshiharu Miura ${ }^{3}$ and Katsushige Iwai ${ }^{1}$
}

\begin{abstract}
:
Progressive multifocal leukoencephalopathy (PML) is a demyelinating disease of the central nervous system caused by reactivation of the JC virus under an immunosuppressed state. This condition carries a high risk of cryptococcal meningitis. We herein report a 65 -year-old woman who simultaneously developed PML and cryptococcal meningitis and presented with bilateral sixth nerve palsy. She had been treated with methotrexate and infliximab for rheumatoid arthritis. Her symptoms improved with antifungal drug treatment and discontinuation of immunosuppression therapy. Although concurrent PML and cryptococcal meningitis is rare, it should be considered in immunosuppressed patients.
\end{abstract}

Key words: progressive multifocal leukoencephalopathy, cryptococcal meningitis, infliximab, methotrexate, JC virus

(Intern Med 58: 2703-2709, 2019)

(DOI: 10.2169/internalmedicine.2570-18)

\section{Introduction}

Progressive multifocal leukoencephalopathy (PML) is a demyelinating disease of the central nervous system (CNS) caused by reactivation of the JC virus (JCV). PML often occurs in patients who are immunosuppressed or who are receiving immunosuppression therapy (1). Cryptococcal meningitis is another condition that occurs in immunosuppressed conditions and remains a major cause of human immunodeficiency virus (HIV)-related mortality worldwide (2). Given the recent increase in the use of immunosuppression therapy for rheumatologic conditions, oncology, and organ transplantation, the incidence of PML and cryptococcal meningitis is increasing (3-7).

Two commonly used immunosuppressive drugs are methotrexate (MTX) and infliximab. MTX is an analogue of the B vitamin folic acid that is used as first-line immunosuppression therapy for patients with rheumatoid arthritis (8). Infliximab is a monoclonal chimeric antibody di- rected against soluble and membrane-bound tumor necrosis factor alpha $(\mathrm{TNF} \alpha)$ that prevents receptor binding and blocks gene transcription (9). Although these agents are effective for rheumatoid arthritis, they may increase the risk of opportunistic infections.

We herein report a patient diagnosed with concurrent PML and cryptococcal meningitis while receiving infliximab and methotrexate treatment for rheumatoid arthritis.

\section{Case Report}

A 65-year-old woman was admitted to our hospital because of transient acute right upper limb weakness and gait disturbance. Her medical history revealed that she had been diagnosed with rheumatoid arthritis at 57 years of age and started on $3 \mathrm{mg} / \mathrm{day}$ prednisolone and weekly oral methotrexate $(6 \mathrm{mg})$. At 61 years of age, infliximab had been administered every 8 weeks, and prednisolone was reduced to $2 \mathrm{mg} /$ day. Because of remission, prednisolone had been reduced to $1 \mathrm{mg} /$ day and oral methotrexate to $4 \mathrm{mg}$. At

${ }^{1}$ Department of Neurology, Toyohashi Municipal Hospital, Japan, ${ }^{2}$ Department of Virology 1, National Institute of Infectious Diseases, Japan and ${ }^{3}$ Department of Neurology, Tokyo Metropolitan Cancer and Infectious Diseases Center Komagome Hospital, Japan Received for publication December 25, 2018; Accepted for publication March 24, 2019 Correspondence to Dr. Yasunobu Nosaki, nozaki-yasunobu@toyohashi-mh.jp 
64 years of age, prednisolone was discontinued due to remission of symptoms. Until admission, remission of arthritis symptoms had been maintained with oral methotrexate (4 $\mathrm{mg}$ ) and infliximab $(3 \mathrm{mg} / \mathrm{kg})$. She had no history of diabetes mellitus during the treatment period.

On admission, she was $151 \mathrm{~cm}$ tall and weighed $52.2 \mathrm{~kg}$. She was alert and well oriented. Her cranial nerve function was intact. Slight weakness of the right upper and lower limbs was noted. Although there was no objective sensory loss, she complained of numbness of the right fingers. Her cognitive function was normal, her Revised Hasegawa's Dementia Scale (HDS-R) score was 28 points, and her mini mental state examination score was 30 . Brain computed tomography (CT) showed no hemorrhagic changes. Brain magnetic resonance imaging (MRI) showed no abnormal intensity areas on diffusion-weighted imaging (DWI). Nonspecific lesions were seen on fluid-attenuated inversion recovery (FLAIR) images (Fig. 1A). A neurological examination was normal on the second hospital day, and a transient ischemic attack (TIA) was diagnosed. The patient was discharged four days later as there was no recurrence of limb palsy or TIA symptoms.

After discharge, the patient reported onset of headache and general fatigue. Eight weeks later, she was readmitted with headache, nausea, dizziness, weight loss, and double vision. At that time, her weight was $45 \mathrm{~kg}$, her cognitive function was mildly disturbed, and her HDS-R score was 16 points. A neurological examination revealed a drowsy state and bilateral sixth nerve palsy. Other cranial nerve functions and muscle strength of the extremities were normal. There were no meningeal signs, such as neck stiffness or Kernig's sign. The finger-to-nose and heel-to-knee tests showed no abnormalities. Deep tendon reflexes were slightly increased in the upper and lower extremities. The patient could not walk without assistance due to headache, dizziness, and double vision.

Blood tests showed a normal white blood cell count $(5,400$ cells $/ \mu \mathrm{L}$; reference $3,300-8,600$ cells $/ \mu \mathrm{L})$ with decreased lymphocytes (4.0\%; reference 21.3-50.2\%). Blood chemistry demonstrated normal C-reactive protein and $\beta$-Dglucan levels, and the HIV antibody test were negative. In addition, blood glucose levels were normal (143 mg/dL; reference $60-160 \mathrm{mg} / \mathrm{dL}$ ). A cerebrospinal fluid examination (CSF) revealed an elevated white blood cell count (23 cells/ $\mu \mathrm{L}$, monocyte 22 cells $/ \mu \mathrm{L}$, polymorphonuclear count 1 cell/ $\mu \mathrm{L}$; reference 5 or less cells $/ \mu \mathrm{L}$ ) with an opening pressure of over $30 \mathrm{cmH}_{2} \mathrm{O}$. The protein concentration in the CSF was increased (199 mg/dL; reference 10-45 mg/dL). The glucose level in the CSF was $22 \mathrm{mg} / \mathrm{dL}$, and the ratio of the CSF/ blood glucose was decreased $(0.15$; reference $>0.4)$. Cryptococcal antigen was detected in the CSF and serum. A direct examination with India ink staining of the CSF and CSF culture identified Cryptococcus neoformans.

Brain MRI revealed focal lesions in the white matter of the bilateral frontal and temporal lobes (Fig. 1B). These lesions appeared hyperintense on T2-weighted and FLAIR im- ages and hypointense and devoid of contrast enhancement on T1-weighted images.

The clinical course is summarized in Fig. 2. We diagnosed the patient with cryptococcal meningitis based on the results of the CSF examination. MTX and infliximab were discontinued, and treatment with amphotericin B intravenously in combination with flucytosine was started. After six weeks, induction therapy succeeded, and fluconazole was started for maintenance therapy. Three weeks after starting antifungal therapy, polymerase chain reaction (PCR) targeting the JCV large $\mathrm{T}$ gene in CSF revealed the presence of JCV-DNA showing 479 copies/mL (reference $<50$ copies/ $\mathrm{mL}$ ). The JCV genome in CSF showed a mutation characteristic of the PML-type virus identified in the non-coding control region (NCCR) using multiplex real-time PCR (10). Based on MRI findings and PCR test results for JCV in CSF, we diagnosed her with probable PML. Antifungal therapy was continued without restarting MTX and infliximab, and no other alternative immunosuppressive agents were started. The patient's clinical symptoms gradually improved without recurrence of rheumatoid arthritis. Follow-up MRI performed one month after readmission showed enlargement of some lesions and the appearance of new lesions (Fig. 1C). At that time, DWI showed slight hyperintensity of the lesions and a partial low signal on the apparent diffusion coefficient map.

Given the lack of focal neurological symptoms, we closely monitored the patient's condition without treatment, other than antifungal therapy. Eight weeks after readmission, she was discharged with improvement in double vision. Her cognitive function became normal, and her HDS-R score was 28. Two months after discharge, JCV DNA in CSF was negative, and MRI findings showed slight improvement (Fig. 1D). At the time of writing, the patient had been stable for over six months.

\section{Discussion}

The patient in the present case was diagnosed with PML and cryptococcal meningitis. Brain imaging and CSF examinations at the time of secondary admission revealed Cryptococcus neoformans infection and JCV reactivation. Clinical symptoms of headache, nausea, dizziness, bilateral sixth nerve palsy, and cognitive dysfunction were observed. These symptoms are frequently observed in cryptococcal meningitis (6), and they gradually improve after starting antifungal therapy without the improvement of MRI findings. Therefore, we considered the symptoms of secondary admission to have been caused by cryptococcal meningitis.

PCR of the patient's CSF DNA was positive for JCV, which had the mutation within the NCCR of the viral genome. JCV infection is common in humans and JCV DNA (archetype) is usually found in the blood or urine in non-PML patients. However, JCV variants with NCCR mutations (PML-type) were detected in PML patients (10). Brain MRI revealed focal lesions in the white matter of the 

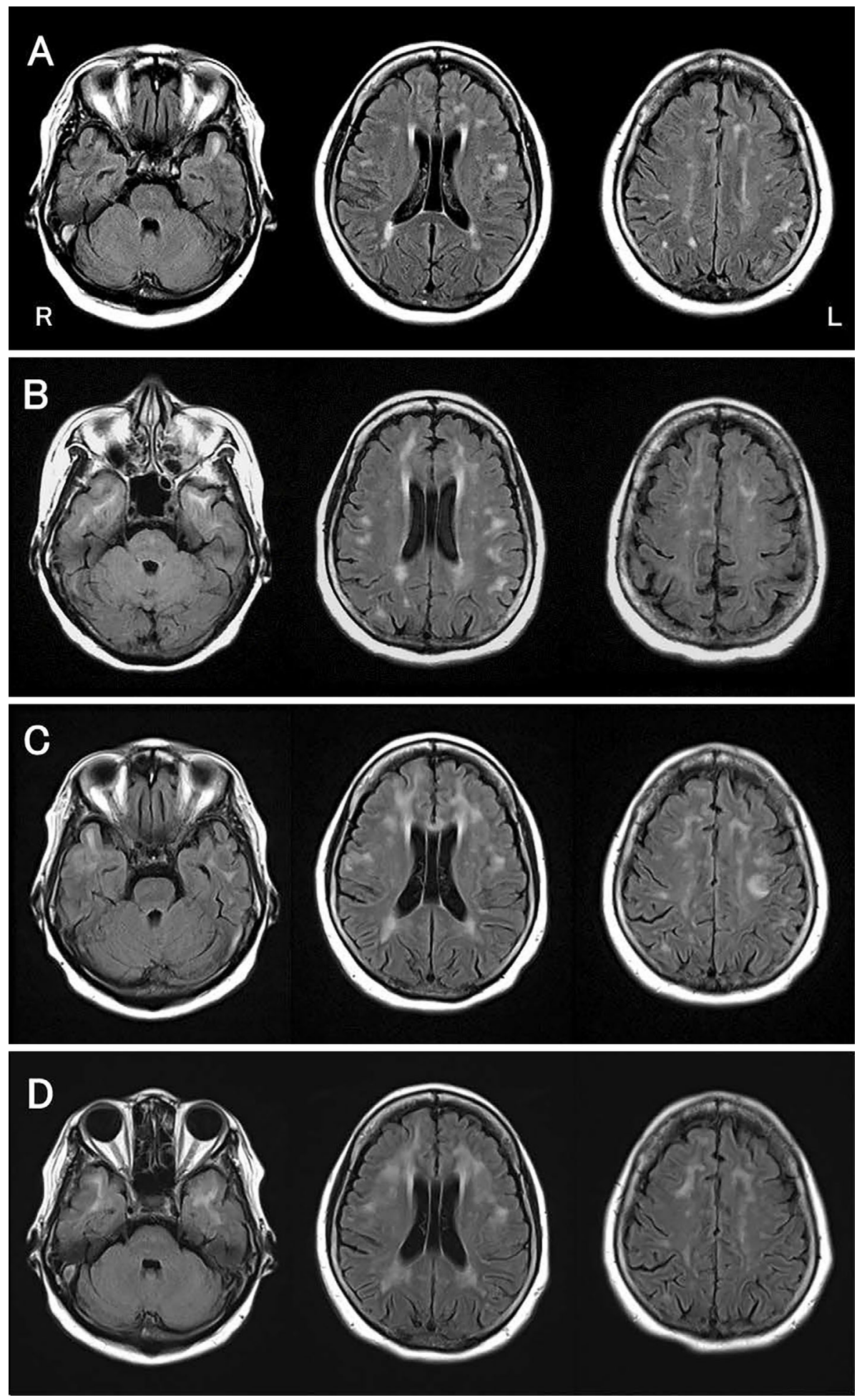

Figure 1. Changes in brain magnetic resonance imaging (MRI) over time. Fluid-attenuated inversion recovery (FLAIR) scans at first admission (A) and two months (B), three months (C), and six months (D) after the first admission. (A) shows nonspecific changes. (B) shows focal lesions in the white matter of the bilateral frontal and temporal lobes. (C) shows that the lesions in the white matter on FLAIR grew. (D) shows that the lesions gradually disappeared, and no new lesions developed.

bilateral frontal and temporal lobes. PML and cryptococcal meningitis were therefore simultaneously diagnosed. To our knowledge, there have been only three cases of PML concurrent with cryptococcal meningitis (11-13; Table). Cases 1 and 2 were diagnosed PML at an autopsy. Prednisone had been used as an immunosuppressive agent in Cases 2 and 3, whereas biologic agents were administered in our case. Antifungal therapy without antiviral drugs was administered as treatment in all cases; however, only our patient survived. Compared with these previous three cases, the patient in the 


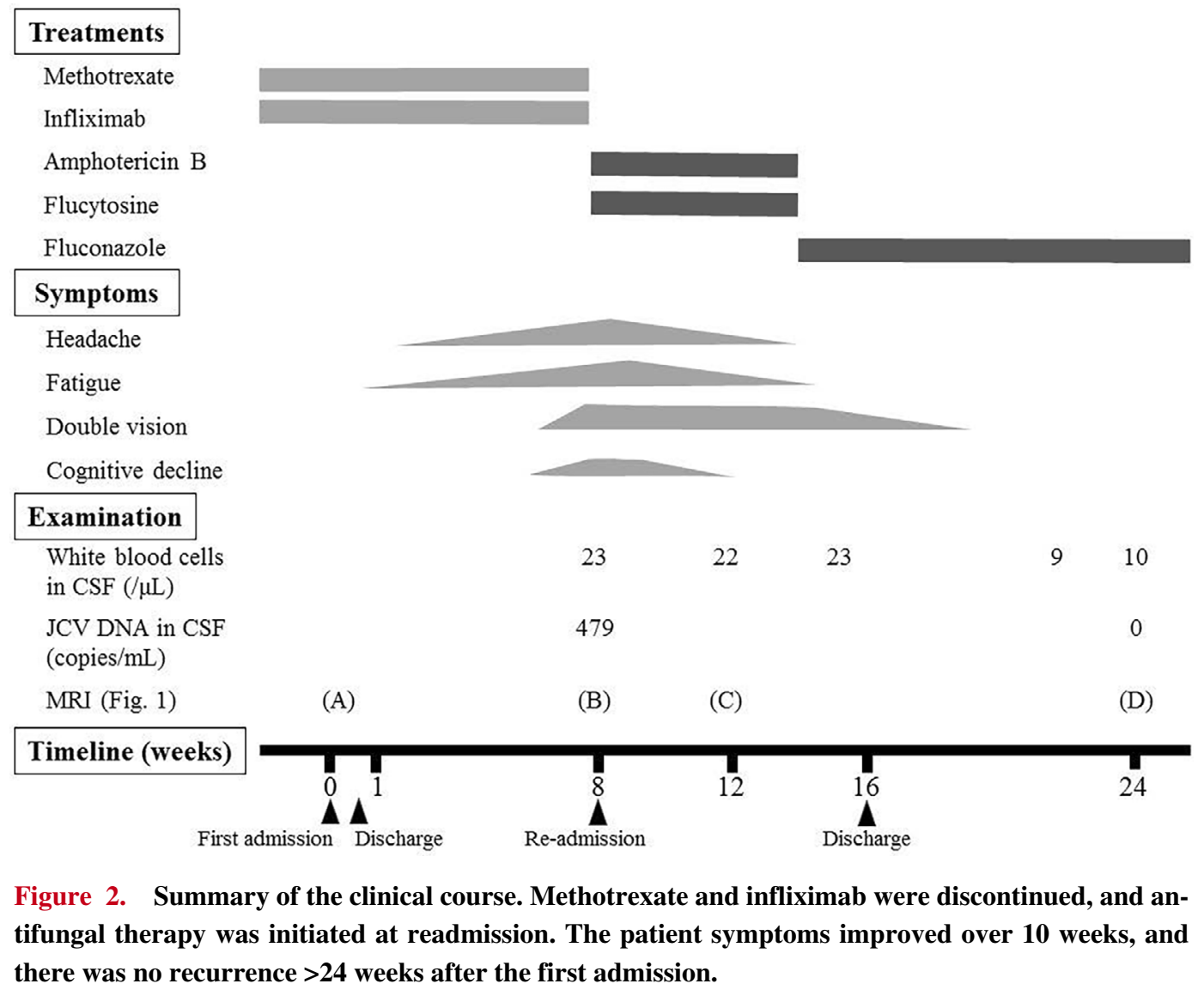

Table. Known Cases of PML Concurrent with Cryptococcal Meningitis.

\begin{tabular}{|c|c|c|c|c|c|c|c|}
\hline Case & $\begin{array}{l}\text { Age (years)/ } \\
\text { Sex }\end{array}$ & $\begin{array}{l}\text { Underlying } \\
\text { diseases }\end{array}$ & $\begin{array}{c}\text { Immunosuppressive } \\
\text { agents }\end{array}$ & $\begin{array}{c}\text { Cryptococcal } \\
\text { meningitis } \\
\text { identified }\end{array}$ & $\begin{array}{c}\text { PML } \\
\text { identified }\end{array}$ & $\begin{array}{c}\text { Treatment/ } \\
\text { Antiviral drugs }\end{array}$ & $\begin{array}{l}\text { Outcome } \\
\text { (interval) }\end{array}$ \\
\hline 1 & $\begin{array}{c}\text { 49/M } \\
\text { (Mathews } \\
1977)\end{array}$ & Sarcoidosis & None & CSF & Autopsy & $\begin{array}{c}\text { Antifungal } \\
\text { therapy and } \\
\text { corticosteroids/ } \\
\text { none }\end{array}$ & $\begin{array}{l}\text { Declined } \\
\text { and died } \\
\quad(60 \\
\text { months })\end{array}$ \\
\hline 2 & $\begin{array}{l}36 / F \\
(\text { Malas } \\
1977)\end{array}$ & $\begin{array}{l}\text { SLE, } \\
\text { Thymoma, } \\
\text { Aplastic } \\
\text { anemia }\end{array}$ & $\begin{array}{l}\text { Prednisone, } \\
\text { Oxymetholone, } \\
\text { Azathioprine, and } \\
\text { Radiotherapy for } \\
\text { thymoma }\end{array}$ & CSF & Autopsy & $\begin{array}{l}\text { Antifungal } \\
\text { therapy/ } \\
\text { none }\end{array}$ & $\begin{array}{c}\text { Died } \\
\text { (5 months) }\end{array}$ \\
\hline 3 & $\begin{array}{c}\text { 61/M } \\
\text { (Weitzman } \\
1978)\end{array}$ & $\begin{array}{c}\text { Poorly } \\
\text { differentiated } \\
\text { lymphocytic } \\
\text { lymphoma }\end{array}$ & $\begin{array}{c}\text { Cyclophosphamide, } \\
\text { Vincristine, and } \\
\text { Prednisone }\end{array}$ & CSF & $\begin{array}{c}\text { CT, } \\
\text { Biopsy }\end{array}$ & $\begin{array}{l}\text { Antifungal } \\
\text { therapy/ } \\
\text { none }\end{array}$ & $\begin{array}{c}\text { Died } \\
\text { (7 months) }\end{array}$ \\
\hline $\begin{array}{l}\text { Present } \\
\text { case }\end{array}$ & $65 / \mathrm{F}$ & $\begin{array}{c}\text { Rheumatoid } \\
\text { arthritis }\end{array}$ & $\begin{array}{l}\text { Methotrexate and } \\
\text { Infliximab }\end{array}$ & CSF & $\begin{array}{c}\text { MRI, JC } \\
\text { virus PCR }\end{array}$ & $\begin{array}{l}\text { Antifungal } \\
\text { therapy/ } \\
\text { none }\end{array}$ & $\begin{array}{l}\text { Survived, } \\
\text { stable } \\
\text { (6 months) }\end{array}$ \\
\hline
\end{tabular}

SLE: systemic lupus erythematosus, CSF: cerebrospinal fluid, PML: progressive multifocal leukoencephalopathy, CT: computed tomography, MRI: magnetic resonance imaging, PCR: polymerase chain reaction

Cases 1, 2, and 3 are from previously published reports (11-13).

present case had a short disease duration prior to the diagnosis of cryptococcal meningitis and PML as well as an early administration of antifungal therapy with the discontinuation of immunosuppressive therapy. We suspect that these factors contributed to her good prognosis.

In our case, brain MRI over time showed gradual changes
(Fig. 1). In HIV-positive patients with cryptococcal meningitis, MRI findings show leptomeningeal enhancement with or without a micronodular pattern, microcystic prominence involving the temporal lobes or basal ganglia, ventriculomegaly, and brain abscess (14). In non-HIV patients with cryptococcal meningitis, Virchow-Robin dilatation, hydro- 
cephalus, intracerebral nodules, and pseudocysts are typically present (15). The MRI findings for our patient differed from those in previous cases of cryptococcal meningitis in all therapy periods. Specifically, PML lesions were seen as a single or multiple hyperintense areas in T2-weighted images with variable shapes and size. Typically, bilateral, asymmetric, multifocal white matter plaque-like lesions that are $\mathrm{T} 1$ hypointense do not show enhancement. There is no edema or mass effect, either. On DWI, the advancing edge of the demyelination is strongly hyperintense. For drug-associated PML, lesions are typically localized supratentorially and not infratentorially, especially in the frontal and parietal lobes. Although atypical MRI findings are common, MRI may still be useful for detecting lesions at an early stage of PML $(16,17)$. In the present case, brain MRI at the initial admission did not show obvious PML lesions. However, the second MRI scan revealed multiple lesions on T2-weighted images and FLAIR hyperintense areas compatible with PML. In addition, the lesions of the bilateral frontal and temporal lobes changed throughout the clinical course.

Cryptococcal meningitis is one of the most important opportunistic infections among immunocompromised hosts, and infection in patients treated with infliximab or MTX has been previously reported (18-21). PML has been reported in patients receiving biologic agents, such as natalizumab, efalizumab, rituximab, and infliximab $(5,7)$. Such biologic immunosuppressive agents are known to have a strong association with drug-induced PML (3). These immunosuppressants are classified into three categories (22-24): Class 1 drugs, including natalizumab, are associated with the highest risk of PML. Class 2 drugs, including rituximab and nonbiologic drugs, such as MTX, are recognized to be associated with a lower risk of PML than class 1 agents. Infliximab and other TNF- $\alpha$ inhibitors are class 3 drugs. The risk of developing PML with class 3 drugs remains uncertain, with one report suggesting that a relationship between PML and treatment with anti-TNF agents is unlikely (25). However, several reports have described an association with PML $(5,26,27)$. In the present case, the blood cell count showed decreased lymphocyte numbers due to immunosuppression therapy with MTX and infliximab. The decreased T lymphocyte numbers impaired cell-mediated immunity, leading to the breakdown of the prevention of JCV reactivation and cryptococcal infection $(6,7,27)$. Therefore, PML should be considered in patients receiving combination therapy with class 2 and 3 agents. In addition, TNF- $\alpha$ inhibitors are known to induce CNS demyelination (28). Although the mechanism is not fully understood, MRI findings from patients treated with TNF- $\alpha$ inhibitors show CNS demyelination as white matter changes on T2-weighted and FLAIR images. This characteristic is similar to PML findings, and we should consider the possibility of PML when changes in MRI findings are noted for patients receiving TNF- $\alpha$ inhibitors.

The recommended approach for drug-induced PML is to exclude suspicious drug use and perform plasma ex- change (17). Although several reports have shown some effectiveness of zidovudine, interferon alpha, foscavir, cidofovir, mitazapine, mefloquine, and comptochecin (29-31), the most effective treatment for PML has not been determined. Therefore, many targeted therapies against PML are presently under study. In our patient, we diagnosed probable PML concurrent with cryptococcal meningitis. After starting antifungal therapy and stopping infliximab and MTX, the clinical symptoms and CSF cell count gradually improved. Plasma exchange and drug treatment for PML were not performed in our patient due to her clinical improvement. MRI findings from long-term survivors of PML show leukomalacia and subcortical atrophy (32), whereas the white matter lesions on MRI in our patient gradually disappeared. Our patient received only an antifungal drug and remained stable over the long term with gradual improvement in MRI findings.

Recently, the occurrence of immune reconstitution inflammatory syndrome (IRIS) has been recognized in association with the treatment of cryptococcal meningitis and PML. IRIS is characterized by a tissue-destructive inflammatory response after initiating highly active antiretroviral therapy (HAART) for HIV or tapering or discontinuing immunosuppressive drugs. IRIS should be considered when clinical symptoms develop and atypical imaging findings are noted despite adequate treatment. IRIS can manifest as cryptococcal meningitis or PML, which is known as cryptococcal meningitis-IRIS or PML-IRIS, respectively. The risk factors of IRIS are pre-treatment HIV or a severe immunosuppressive state with very low CD4 counts and increasing CD4 counts after the initiation of therapy (33). In the present case, IRIS was not observed after the discontinuation of immunosuppressive agents. The patient did not have HIV, and the recovery of her immune function was slow, as the lymphocyte and CD4 cell counts had been decreased for 17 and $>24$ weeks, respectively. We suspected the occurrence of IRIS was prevented by these characteristics.

We also evaluated JCV with mutation within the NCCR of the viral genome. Many kinds of rearranged NCCR of JCV variants (PML-type) have been reported, and the frequent NCCR typing changed in accordance with either the vial load or therapeutic intervention. The NCCR of JCV variants can be used to evaluate PML progression, and changes in NCCR typing can be used as a biomarker of PML treatment in the future (34).

In summary, we encountered a case of simultaneous development of PML and cryptococcal meningitis in a patient receiving MTX and infliximab. All patients treated with immunosuppressive therapy, including monoclonal antibodies, require careful monitoring, and if neurological symptoms are noted, CNS infection should be considered. In particular, multiple infections should be considered in immunosuppressed patients.

The authors state that they have no Conflict of Interest (COI). 


\section{Financial Support}

This work was supported in part by JSPS KAKENHI (Grant Number 17K09768) and a Grant-in-Aid for the Research Committee of Prion Disease and Slow Virus Infection, Research on Policy Planning and Evaluation for Rare and Intractable Diseases from the Ministry of Health, Labour and Welfare of Japan (Grant Number H29-Nanchitou (Nan)-Ippan-036).

\section{References}

1. Nakamichi K, Mizusawa H, Yamada M, et al. Characteristics of progressive multifocal leukoencephalopathy clarified through internet-assisted laboratory surveillance in Japan. BMC Neurol 12: 121, 2012.

2. Park BJ, Wannemuehler KA, Marston BJ, Govender N, Pappas PG, Chiller TM. Estimation of the current global burden of cryptococcal meningitis among persons living with HIV/AIDS. AIDS 23: 525-530, 2009.

3. Piccinni C, Sacripanti C, Poluzzi E, et al. Stronger association of drug-induced progressive multifocal leukoencephalopathy (PML) with biological immunomodulating agents. Eur J Clin Pharmacol 66: 199-206, 2010.

4. Pyrgos V, Seitz AE, Steiner CA, Prevots DR, Williamson PR. Epidemiology of cryptococcal meningitis in the US: 1997-2009. Plos One 8: 390-396, 2013.

5. Sammut L, Wallis D, Holroyd C. Progressive multifocal leukoencephalopathy associated with infliximab. J R Coll Physicians Edinb 46: 163-165, 2016.

6. Qu J, Zhou T, Zhong C, Deng R, Lü X. Comparison of clinical features and prognostic factors in HIV-negative adults with cryptococcal meningitis and tuberculous meningitis: a retrospective study. BMC Infect Dis 17: 51, 2017.

7. Bohra C, Sokol L, Dalia S. Progressive multifocal leukoencephalopathy and monoclonal antibodies: a review. Cancer Control 24: 19, 2017.

8. Smolen JS, Landewé R, Bijlsma J, et al. EULAR recommendations for the management of rheumatoid arthritis with synthetic and biological disease-modifying antirheumatic drugs: 2016 update. Ann Rheum Dis 76: 960-977, 2017.

9. Maini RN, Feldmann M. How does infliximab work in rheumatoid arthritis? Arthritis Res 4: S22-S28, 2002.

10. Ryschkewitsch CF, Jensen PN, Major EO. Multiplex qPCR assay for ultra sensitive detection of JCV DNA with simultaneous identification of genotypes that discriminates non-virulent from virulent variants. J Clin Virol 57: 243-248, 2013.

11. Mathews T, Wisotzkey H, Moossy J. Multiple central nervous system infections in progressive multifocal leukoencephalopathy. Neurology 26: 9-14, 1976.

12. Malas D, Weiss S. Progressive multifocal leukoencephalopathy and cryptococcal meningitis with systemic lupus erythematosus and thymoma. Ann Neurol 1: 188-191, 1977.

13. Weitzman S, Kaufman S, Wolpow E, Hinton RC, Richardson EP Jr. Case report. Simultaneous fungal and viral infection of the central nervous system. Am J Med Sci 276: 127-132, 1978.

14. Sarkis RA, Mays M, Isada C, Ahmed M. MRI findings in cryptococcal meningitis of the non-HIV population. Neurologist 19: 4045, 2015.

15. Zhong Y, Zhou Z, Fang X, Peng F, Zhang W. Magnetic resonance imaging study of cryptococcal neuroradiological lesions in HIVnegative cryptococcal meningitis. Eur J Clin Microbiol Infect Dis 36: 1367-1372, 2017.

16. Sahraian MA, Radue EW, Eshaghi A, Besliu S, Minagar A. Progressive multifocal leukoencephalopathy: a review of the neuroimaging features and differential diagnosis. Eur J Neurol 19: 1060-
1069, 2012.

17. Williamson EML, Berger JR. Diagnosis and treatment of progressive multifocal leukoencephalopathy associated with multiple sclerosis therapies. Neurotherapeutics 14: 961-973, 2017.

18. Baughman RP, Lower EE. Fungal infections as a complication of therapy for sarcoidosis. QJM 98: 451-456, 2005.

19. Kluger N, Poirier P, Guilpain P, Baixench MT, Cohen P, Paugam A. Cryptococcal meningitis in a patient treated with infliximab and mycophenolate mofetil for Behçet's disease. Int J Infect Dis 13: e325, 2009.

20. Trillos RF, Fernández-Ávila DG, Díaz MC, Gutiérrez JM. Cryptococcal meningoencephalitis in a patient with rheumatoid arthritis treated with methotrexate and prednisone. Reumatol Clin 10: 346347, 2014.

21. Vasant DH, Limdi JK, Borg-Bartolo SP, Bonington A, George R. Posterior reversible encephalopathy syndrome and fatal cryptococcal meningitis after immunosuppression in a patient with elderly onset inflammatory bowel disease. ACG Case Rep J 3: e98, 2016.

22. Zaheer F, Berger JR. Treatment-related progressive multifocal leukoencephalopathy: current understanding and future steps. Ther Adv Drug Saf 3: 227-239, 2012.

23. Calabrese LH, Molloy E, Berger J. Sorting out the risks in progressive multifocal leukoencephalopathy. Nat Rev Rheumatol 11: 119-123, 2015.

24. Clavel G, Moulignier A, Semerano L. Progressive multifocal leukoencephalopathy and rheumatoid arthritis treatments. Joint Bone Spine 84: 671-675, 2017.

25. Molloy ES, Calabrese LH. Progressive multifocal leukoencephalopathy associated with immunosuppressive therapy in rheumatic diseases: evolving role of biologic therapies. Arthritis Rheum 64: 3043-3051, 2012.

26. Kumar D, Bouldin TW, Berger RG. A case of progressive multifocal leukoencephalopathy in a patient treated with infliximab. Arthritis Rheum 62: 3191-3195, 2010.

27. Keene DL, Legare C, Taylor E, Gallivan J, Cawthorn GM, Vu D. Monoclonal antibodies and progressive multifocal leukoencephalopathy. Can J Neurol Sci 38: 565-571, 2011.

28. Solomon AJ, Spain RI, Kruer MC, Bourdette D. Inflammatory neurological disease in patients treated with tumor necrosis factor alpha inhibitors. Mult Scler 17: 1472-1487, 2011.

29. Kishida S, Tanaka K. Mefloquine treatment in a patient suffering from progressive multifocal leukoencephalopathy after umbilical cord blood transplant. Intern Med 49: 2509-2513, 2010.

30. Sano Y, Nakano Y, Omoto M, et al. Rituximab-associated progressive multifocal leukoencephalopathy derived from non-Hodgkin lymphoma: neuropathological findings and results of mefloquine treatment. Intern Med 54: 965-970, 2015.

31. Pavlovic D, Patera AC, Nyberg F, Gerber M, Liu M; Progressive Multifocal Leukeoncephalopathy Consortium. Progressive multifocal leukoencephalopathy: current treatment options and future perspectives. Ther Adv Neurol Disord 8: 255-273, 2015.

32. Lima MA, Bernal-Cano F, Clifford DB, Gandhi RT, Koralnik IJ. Clinical outcome of long-term survivors of progressive multifocal leukoencephalopathy. J Neurol Neurosurg Psychiatry 81: 12881291, 2010.

33. Post MJ, Thurnher MM, Clifford DB, et al. CNS-immune reconstitution inflammatory syndrome in the setting of HIV infection, part 1: overview and discussion of progressive multifocal leukoencephalopathy-immune reconstitution inflammatory syndrome and cryptococcal-immune reconstitution inflammatory syndrome. AJNR Am J Neuroradiol 34: 1297-1307, 2013.

34. Nakamichi K, Kishida S, Tanaka K, et al. Sequential changes in the non-coding control region sequences of JC polyomaviruses from the cerebrospinal fluid of patients with progressive multifocal leukoencephalopathy. Arch Virol 158: 639-650, 2013. 
The Internal Medicine is an Open Access journal distributed under the Creative

by-nc-nd/4.0/). Commons Attribution-NonCommercial-NoDerivatives 4.0 International License. To view the details of this license, please visit (https://creativecommons.org/licenses/

(C) 2019 The Japanese Society of Internal Medicine Intern Med 58: 2703-2709, 2019 